TITLE:

\title{
Convection and precipitation under various stability and shear conditions: Squall lines in tropical versus midlatitude environment
}

\author{
AUTHOR(S): \\ Takemi, Tetsuya
}

\section{CITATION:}

Takemi, Tetsuya. Convection and precipitation under various stability and shear conditions: Squall lines in tropical versus midlatitude environment. Atmospheric Research 2014, 142: 111-123

ISSUE DATE:

2014-06-01

URL:

http://hdl.handle.net/2433/189099

\section{RIGHT:}

(C) 2013 Elsevier B.V.; This is not the published version. Please cite only the published version:; この論文は出版社版でありません。引用の際に は出版社版をご確認ご利用ください。 
Convection and precipitation under various stability and shear conditions:

Squall lines in tropical versus midlatitude environment

Tetsuya Takemi

Disaster Prevention Research Institute, Kyoto University, Uji, Kyoto, Japan

Submitted: March 2013

revised: July 2013

Corresponding author: Tetsuya Takemi, Disaster Prevention Research Institute, Kyoto University, Gokasho, Uji, Kyoto 611-0011, Japan.

Email: takemi@storm.dpri.kyoto-u.ac.jp

Tel: +81-774-38-4160

Fax: $+81-774-38-4158$ 


\section{ABSTRACT}

This study investigates the sensitivity of the structure and intensity of squall lines to the vertical profile of temperature and moisture that are intended to represent a tropical, oceanic, and a midlatitude, continental environment by conducting a set of numerical experiments with a nonhydrostatic atmospheric model at a convection-resolving resolution. In the experiments the vertical distributions of convective available potential energy (CAPE) for air parcels originating at various heights are controlled by changing relative humidity for the tropical and the midlatitude condition. It was shown that the strength and areal extent of updrafts within the simulated squall lines are significantly regulated by environmental temperature lapse rate. A condition with a larger lapse rate leads to the development of widespread, strong updrafts. The difference in the vertical profile of buoyancy for lifted air parcels is a key to delineate the difference in the updraft statistics under different thermodynamic conditions. In contrast, it was found that the precipitation amount is controlled by the vertical distribution of CAPE. The precipitation amount increases with the increase in the depth of the layer having a significant amount of CAPE.

Keyword: squall line; precipitation; stability; CAPE; mesoscale meteorological model

Highlights:

We compare the structure and intensity of squall lines in a tropical, oceanic, and a midlatitude, continental environment.

We examine CAPE for air parcels originating not only at the surface but also at elevated levels.

The strength and areal extent of updrafts are significantly regulated by environmental temperature lapse rate.

The precipitation amount increases with the increase in the depth of the layer having a significant 
amount of CAPE.

Diagnosing thermodynamic environment explains convective intensity at the mature stage but not the initiation of convection.

\section{Introduction}

Mesoscale convective systems (MCSs) are one of the major meteorological hazards throughout the world. The structure and intensity of MCSs are significantly regulated by their environmental meteorological conditions such as the spatial fields of wind, temperature, and moisture (e.g., Houze, 1993; Cotton et al., 2011). These environmental conditions are determined by synoptic-scale and/or larger-scale meteorological settings that develop in various climates ranging from the tropics, sub-tropics, mid-latitude regions, and arid/semi-arid regions. In these climates, MCSs occur over both continental and oceanic regions. Because of the diversity of the climates over the globe, the meteorological settings that host mesoscale convective phenomena have a wide variety which is characterized by the horizontal and vertical distribution of wind, temperature, and moisture.

Among MCSs, squall lines have gained much attention for their significant organized nature and their impacts to society. Although a large number of studies have investigated the various aspects of squall lines in a certain specific region of the world, fewer studies compared and investigated the characteristics of squall lines that develop in different climate regions. Some studies investigated the difference between tropical and midlatitude squall lines from the perspective of atmospheric heating and water budget (Tao et al., 1993; Chin et al., 1995; Ferrier et al., 1996) and convective morphology (Laing and Fritsch, 1997; Guy et al., 2011; Meng et al., 2013).

One of the major differences between the tropics and midlatitude environment is temperature lapse rate. Because of the difference in temperature lapse rate, the melting level is different between tropical and midlatitude squall lines; therefore, the impact of melting processes affects differently tropical and midlatitude squall lines (Tao et al., 1995). Another important point for the difference 
between tropical and midlatitude convection is the vertical velocity field. It is well known that the intensity (size) of updrafts and downdrafts is significantly weaker (smaller) in the tropical convection than in the midlatitude one (Zipser and LeMone, 1980; Jorgensen and LeMone 1989; Lucas et al., 1994a, 1994b; Igau et al., 1999). Lucas et al. (1994a) suggested that the weaker vertical velocities in the tropical convective clouds are due to smaller buoyancy from more effective water loading and entrainment than those in the midlatitude counterparts; it is recognized that the midlatitude environments are characterized by large buoyancy while the tropical environments are by small buoyancy.

The vertical distribution of buoyancy is considered to play an important role in determining the intensity of convective systems (e.g., Lucas et al., 1994b; Takemi and Satomura, 2000; Takemi, 2010). If the buoyancy becomes smaller throughout the troposphere, the upward acceleration of air parcels becomes also smaller. Then it would take a longer period of time for the air parcels to be raised from the low levels to the upper levels. In this case, the updraft parcels will experience more dilution by the environmental air, which leads to the deceleration of the upward motion. On the other hand, stronger updrafts resulted from larger buoyancy are less diluted by the environmental air, sustaining their strength until reaching the buoyancy equilibrium level.

Another aspect for the difference in the vertical distribution of buoyancy is how the buoyancy differs for air parcels originating at different levels. Most of the studies assess the buoyancy only for an air parcel at the lowest level or at a level representing boundary-layer characteristics. Takemi (2007a; 2010) investigated the impact of the temperature lapse rate on the intensity of squall lines by conducting numerical experiments of squall lines under idealized settings and emphasized the importance of the vertical distribution of buoyancy for air parcels originating at different levels in diagnosing the structure and intensity of squall lines. This vertical buoyancy distribution is represented by the vertical distribution of convective available potential energy (CAPE) for air parcels originating at different levels (Takemi, 2010), and thus the vertical profile of CAPE can be a good measure to characterize the environmental static stability. Although the studies of Takemi 
$(2007 a ; 2010)$ showed the sensitivity of squall lines to temperature lapse rate that is intended to represent the tropical and midlatitude environments, the temperature lapse rate examined as a representative of the tropical environment was much larger than the observed tropical atmosphere (see Fig. 1 of Takemi (2010)). Since the magnitude of buoyancy depends on the temperature lapse rate, the impacts of temperature lapse rate that closely follows an observed environment in the tropics should be further investigated. Furthermore, in the study of Takemi (2010), the impacts of changing the vertical distribution of CAPE on the simulated squall lines were not actually separated from those of changing the temperature lapse rate, which requires us to explore the effects of temperature lapse rate for the tropical and the midlatitude environment by controlling the CAPE distribution.

The purpose of this study is to investigate the sensitivity of the structure and intensity of squall lines to the vertical profiles of temperature and moisture that represent tropical, oceanic and midlatitude, continental environments. We conduct a set of numerical experiments of squall lines under conditions with various combinations of the vertical profiles of temperature, moisture, and wind by using a nonhydrostatic cloud model in an idealized setup at a convection-resolving resolution. A special focus in determining the environmental conditions is given to the vertical distribution of CAPE assessed for air parcels originating at different levels. In order to elucidate the impacts of temperature lapse rate between the tropical and the midlatitude environment, we set similar distribution of CAPE between the two environments by controlling the vertical profile of moisture within the range found in the real atmosphere.

\section{Numerical model and experimental design}

The atmospheric model used in the present numerical experiments is a version of the Weather Research and Forecasting (WRF) model, the Advance Research WRF (ARW) model version 3.1.1 (Skamarock et al., 2008), which is a nonhydrostatic, compressible atmospheric model. The 
numerical experiments are configured for idealized conditions, following the philosophy of Rotunno et al. (1988), Weisman et al. (1988), and Weisman and Rotunno (2004). In line with their studies and our previous studies (Takemi, 2006; 2007a; 2007b; 2010) with idealized numerical experiments, we set the model configuration as having no Coriolis force, no surface fluxes, and no atmospheric radiation. In addition, we assume that the base-state atmosphere of the model is horizontally homogeneous.

Because of the idealization, the physics processes included are only cloud-microphysics and turbulent mixing. Cloud microphysics processes are parameterized by the scheme of Tao et al. (1989) and Tao et al. (2003), which takes into account the mixing ratios of water vapor, cloud water, rainwater, cloud ice, snow, and graupel as water variables. The turbulence mixing is parameterized by the Deardorff (1980) scheme which solves the prognostic equation of turbulent kinetic energy in determining the eddy viscosity and eddy diffusivity in the three dimensions. The coefficient in the eddy viscosity formulation is set to be 0.15 , based on the study of Takemi and Rotunno (2003).

The grid spacings of the numerical experiments are $500 \mathrm{~m}$ in the horizontal directions and 45-900 $\mathrm{m}$, stretched with height, with 116 levels in the vertical direction in the computational domain of $300 \mathrm{~km}$ (east-west, referred to as $x$ axis) by $60 \mathrm{~km}$ (north-south, $y$ axis) by $23 \mathrm{~km}$ (vertical, $z$ axis). The lateral boundary conditions are periodic at the north and south boundaries and open at the east and west boundaries. The lower boundary is free slip, while the upper boundary is rigid with a Rayleigh-type damping layer imposed in the upper 5-km layer.

The base-state is determined by thermodynamic profiles that are intended to represent the tropical, oceanic environment and the midlatitude, continental environment. The temperature profile of a tropical, oceanic environment is prescribed with a radiosonde sounding for a squall line over the tropical western Pacific (Trier et al., 1996). This environment is hereinafter referred to as TROPICS. On the other hand, the midlatitude, continental profile is given with an analytical function that is a representative of the environment for midlatitude convective storms (Weisman and Klemp, 1982); this analytical sounding has been widely used in investigating midlatitude squall lines (Rotunno et 
130 al., 1988; Weisman et al., 1988; Weisman and Rotunno, 2004). This profile is referred to as

131 MIDLAT.

132 The moisture profile for the TROPICS environment is determined with a tropical observation; the observed data listed in Trier et al. (1996) are used. The case studied in Trier et al. (1996) is a tropical squall line over the tropical western Pacific during the field observation of the Tropical Ocean Global Atmosphere-Coupled Ocean Atmosphere Response Experiment (TOGA-COARE) in February 1993 and has extensively been investigated in the literature (e.g, Redelsperger et al. 2000). On the other hand, the MIDLAT moisture profile is determined based on the analytical sounding (Weisman and Klemp, 1982) and is divided into two types: a moist type (the original Weisman-Klemp humidity profile, referred to as MIDLATM) and a dry type (reduced humidity from the Weisman-Klemp profile, referred to as MIDLATD). The idea to define the dry type profile, MIDLATD, is to keep the vertical distribution of CAPE unchanged between the TROPICS and the MIDLATD environment. The relative humidity profile of MIDLATM is basically the same as the analytical function of Weisman and Klemp (1982), except for the levels near the surface: the relative humidity at the lowest level for the MIDLATM case is intentionally increased in order for the CAPE value of the air parcel originating at that level to be similar to those of MIDLATD and TROPICS. The thermodynamic conditions of MIDLATM and MIDLATD are characterized by the same CAPE value for the surface air parcel but by different CAPE distribution for elevated parcels above the surface level. The vertical profiles of potential temperature and relative humidity for the TROPICS, the MIDLATM, and the MIDLATD case are shown in Fig. 1. With these temperature and humidity profiles, precipitable water content is $46.1 \mathrm{~mm} \mathrm{~m}^{-2}$ for MIDLATM, $38.7 \mathrm{~mm} \mathrm{~m}^{-2}$ for MIDLATD, and $63.0 \mathrm{~mm} \mathrm{~m}^{-2}$ for TROPICS. The vertical distribution of CAPE for an air parcel at each level is shown in Fig. 2. It is noted that the CAPE value is computed with the use of virtual temperature (Doswell and Rassmussen, 1994). It is seen that the CAPE distribution is nearly the same in TROPICS and MIDLATD.

It is known that the intensity of the shear in the lower and middle layer of the troposphere, which 
156 is oriented perpendicular to squall lines, has a major impact on the organization and structure of

157 squall lines (e.g., Weisman and Rotunno, 2004). Therefore, in the present experiments we set the 158 uni-directional shear profile in the lower layer (i.e., the height between 0 and $2.5 \mathrm{~km}$, referred to as low-level shear) or in the middle layer (i.e., the height between $2.5-5 \mathrm{~km}$, referred to as mid-level shear) or in the deep layer (i.e., the height between 0-5 km, referred to as deep shear) as shown in Fig. 3. A weak and a strong shear are prescribed over the depth of $2.5 \mathrm{~km}$ in the lower layer (Fig. 3a) and the middle layer (Fig. 3b): the difference of $5 \mathrm{~m} \mathrm{~s}^{-1}$ in the $2.5-\mathrm{km}$ layer is referred to as a weak shear and the difference of $15 \mathrm{~m} \mathrm{~s}^{-1}$ as a strong shear. On the other hand, a single shear profile is examined as the deep shear: $10 \mathrm{~m} \mathrm{~s}^{-1}$ in the lowest $5 \mathrm{~km}$ (Fig. 3c), which is intended to keep the intensity of shear the same with the weak shear. For each thermodynamic profile (TROPICS, MIDLATM, and MIDLATD), these five shear profiles are defined.

Furthermore, the initial disturbances are given by both warm and cold linear-type potential temperature perturbation aligned in the north-south direction placed at the center point in the $x$ axis. The peak of potential temperature perturbation from the base state is $+3 \mathrm{~K}$ for the warm thermal and $-3 \mathrm{~K}$ for the cold pool; the perturbation shape for the both disturbances is prescribed by an elliptical function, centered at the surface and with the semi-minor axis of $2 \mathrm{~km}$ in the $z$ direction and the semi-major axis of $20 \mathrm{~km}$ in the $x$ direction. The set of experiments initialized by the warm line thermal is referred to as W-type, while that initialized by the linearly oriented cold pool is as C-type. Taking into account the different initialization, the thermodynamic profiles, and the shear profiles, we perform five sets of experiments (TROPICS-W, TROPICS-C, MIDLATD-W, MIDLATD-C, MIDLATM-W) with five different shear profiles. Note that we examine only warm thermal initialization for the MIDLATM case because this thermodynamic profile is quite unstable and is not sensitive to the warm or cold initialization. Thus, the total number of the numerical experiments conducted here is 25 . Table 1 summarizes the thermodynamic profiles and the initializations of the present numerical experiments. The integration time period for each experiment is 6 hours, and the model outputs are done at 5 minutes interval. The analyses are made for the model outputs between 
2 and 6 hours.

\section{Results}

\subsection{Structure and intensity of squall lines}

The overall characteristics of the structure and intensity of the simulated squall lines under different thermodynamic and shear conditions are first demonstrated. Depending on the initialization method, that is, either warm thermal or cold pool, the initial convective cells developed from the warm thermal or at the leading edge of the spreading cold pool. Within 2 hours from the initial time, second-generation cells developed and intensified, producing evaporatively cooled cold pools. Convective organization became evident later times, and the surface cold pool began to spread both eastward and westward direction, except for some thermodynamic and shear cases.

As a measure of the intensity of convection, Fig. 4 compares the fields of vertical velocity at the 3-km height at 4 hours from the initial time for the deep shear case. Note that the simulated convective clouds for all the cases shown in Fig. 4 move eastward. The location of the surface gust front of the eastward-moving cold pool is also indicated. The gust front is defined as a line where the anomaly of virtual potential temperature becomes $-1 \mathrm{~K}$. It is seen that the case with the most active convective motion is MIDLATM-W. Compared with this case, updrafts and downdrafts in the TROPICS and the MIDLATD environments are significantly weaker. The MIDLATD-C case produces relatively strong vertical motion fields among the cases, while there is virtually no convective organization in the MIDLATD-W case. In this way, a sharp sensitivity to initialization is found for the MIDLATD profile. On the other hand, the TROPICS environment produced weaker vertical motion and more scattered updraft cells than in the MIDLATM-W and the MIDLATD-W case; however, there is less sensitivity to the initialization in the TROPICS environment than in the 
MIDLATD. Although the CAPE profiles of TROPICS and MIDLATD are similar (Fig. 2), the relative humidity below the 6 -km height is significantly different between the two environments. In Takemi (2006; 2007b), it was indicated that convective development was seen only in certain shear cases when the lower layer became drier. A sharper sensitivity of convection development to initialization found in MITLATD seems to be related to the humidity in the lower layer. This point is discussed later in section 3.2.

Corresponding to the vertical motion field indicated in Fig. 4, cloud development is also quite sensitive to the thermodynamic profile and the initialization method. Fig. 5 demonstrates the spatial distribution of total condensed water content (i.e., the sum of cloud water, rainwater, cloud ice, snow, and graupel) at the 3-km height at 4 hours for the same cases with those shown in Fig. 4 . The difference in the organization of convective clouds is clearly seen. The MIDLATM-W case produces the most abundant and densely distributed water content, and the MIDLATD-C case also simulates active development of clouds. Again, a strong sensitivity to the initialization method is seen for the MIDLATD environment. On the other hand, the cases with the TROPICS condition indicate relatively small differences between the warm and the cold initialization. It is seen in the TROPICS cases that the case with the cold initialization exhibits a more linearly organized structure in the north-south direction than the warm-initialization case. In the system in the TROPICS-C case (Fig. 5b), active convective clouds are located in the frontward of the system, and clouds associating with no significant vertical motion (see Fig. 4b) spread in the rearward of the system. This feature is not seen for the system in the TROPICS-W case (Fig. 5a). As described later in section 3.2, the intensity of cold pool is weaker in TROPICS-C than in TROPICS-W. It is thus suggested that mechanisms other than the cold-pool forcing, such as upward displacement of gravity waves in the moist environment (Fovell et al., 2006), may play a role in TROPICS-C.

As described previously, the shear profile affects the structure and intensity of squall lines. For the comparison with the deep shear case, Fig. 6 shows the spatial distribution of total condensed water at the $3-\mathrm{km}$ height at 4 hours for the low-level, weak shear cases. Note that the shear intensity, 
namely, wind difference over a unit depth, is the same between the deep shear and the low-level, weak shear. With this shear profile, the most active convection is seen for the MIDLATM-W case (Fig. 6c). For the MIDLATD thermodynamic profile, the case with the cold initialization (Fig. 6e) produces active convective cells. The warm-initialization case still produces convective cells (Fig. 6d), even though their intensity is weaker than with the cold initialization. For the TROPICS thermodynamic profile, the difference between the initialization methods (Figs. 6a and 6b) appears to be smaller, in contrast to the MIDLATD cases.

These features simulated with the low-level, weak shear seem to be similar to those found with the deep shear: the most active case among the five thermodynamic conditions is MIDLATM-W; and sharper sensitivity to the initialization method is seen in the MIDLATD cases than in the TROPICS cases. However, there are some differences between the low-level, weak shear case and the deep shear case. One is that in the MIDLATM-W case cells within the system become more elongated in the $x$ direction (i.e., perpendicular to the convective line) with the low-level, weak shear than with the deep shear, which is consistent with the previous studies (Weisman and Rotunno, 2004; Takemi, 2010). Another point is that under the MIDLATD-W thermodynamic condition (Fig. $5 \mathrm{~d}$ and $6 \mathrm{~d}$ ) convective cells develop with the low-level shear but do not with the deep shear. In this way, the cases with the midlatitude environments indicate pronounced sensitivity to the shear profile and the initialization method. In the cases with the tropical environments, on the other hand, the sensitivity of the structure and organization of the simulated convective systems to the shear (compare Figs. 5a and 6a, and Figs. 5b and 6b) and the initialization (compare Figs. 5a and 5b, and Figs. $6 \mathrm{a}$ and $6 \mathrm{~b})$ is seen to be smaller than that in the midlatitude cases.

From these comparisons, it is found that the sensitivities to shear profile and initialization method appear differently either in the midlatitude environment and the tropical environment. These characteristics of the sensitivity to shear and initialization are further explored in the next subsection. 


\subsection{Statistics of updraft and precipitation}

In order to elucidate the impacts of the thermodynamic environments and the shear profile on the structure and intensity of the simulated squall lines, the statistical properties of updraft, precipitation intensity, and cold-pool intensity are calculated as conducted previously (Weisman et al., 1988; Weisman and Rotunno, 2004; McCaul et al., 2005; Takemi, 2007a; Takemi, 2010). For the statistical calculations, the model outputs over the whole computational domain during the simulated time period between 2 and 6 hours are used. One point to note here is: because the cold pool spread both eastward and westward convective cells develop at or near the leading edges of both eastward-moving and westward-moving cold pools especially at the early stage. However, the westerly shear profiles prescribed in the experiments favor cell developments over the eastward-moving cold pool. Thus, the statistics for the whole computational domain are mostly due to the effects from the convective cells developed over the eastward-moving cold pool.

The maximum updraft speed within the whole computational domain was extracted at each output time, and from the time series of the extracted maximum updraft speeds the temporal mean and the standard deviation were computed. Fig. 7 shows the means and the standard deviations obtained from the time series of the maximum updraft speed for all the numerical experiments. As identified in section 3.1, the MIDLATM-W case produced the strongest updrafts among all the thermodynamic conditions for all the shear profiles. The comparison between the MIDLATD cases and the TROPICS cases for each shear profile indicates that there is different behavior between the low-level shear cases and the mid-level shear cases. As is consistent with the results shown in section 3.1, the maximum updraft is stronger in the MIDLATD environment than in the TROPICS environment in the low-level shear cases, which is consistent with the observed fact that updraft peak is in general much stronger in the midlatitude than in the tropics (Zipser and LeMone, 1980; Jorgensen and LeMone, 1989; Igau et al., 1999). If the shear is elevated above the $2.5-\mathrm{km}$ height, on the other hand, the maximum updrafts in the TROPICS environment are comparable to or even 
greater than those in the MIDLATD environment. The stronger maximum updrafts simulated in the tropical environment than in the midlatitude environment for the elevated shear cases appear to disagree with the above observational facts. The apparent contradiction in the representation of maximum updraft in the TROPICS and MIDLATD experiments is due to significantly less active development of convective clouds in MIDLATD than in MIDLATM: the degree of convective organization in the MIDLATD cases is basically quite low. Note that the maximum updraft in TROPICS is still much weaker than that in MIDLATM-W. Actually, the maximum updrafts found in the observations were obtained from deep convective clouds that typically developed under surface-based shears and in weaker-shear environments for the tropical than the midlatitude region, while in the present experiments the same elevated shear is prescribed.

The characteristics seen in Fig. 7 are further examined through the vertical distribution of updraft strength and size. As done in Takemi (2007a), updrafts are defined as having a magnitude of greater than or equal to $1 \mathrm{~m} \mathrm{~s}^{-1}$. This approach is used because this identification was employed in the observational studies of LeMone and Ziper (1980) and Wei et al. (1998). At each height, the vertical speeds at grids identified as the updraft were spatially averaged over the total updraft grids, and the maximum speed was also chosen. In addition, the areal coverage of updraft cells was calculated. This calculation was done for all the model output times during 2 and 6 hours, and the means and maxima were temporally averaged.

Fig. 8 shows the vertical distributions of the mean and maxima of updrafts and the areal coverage of updraft grids for the deep shear case. In general, the means and maxima of updraft are the strongest in the MIDLATM-W case, followed by the MIDLATD-C case, while the updrafts in the TROPICS cases are much weaker. The updrafts in the MIDLATD-W case exhibits the weakest among the thermodynamic cases, which corresponds to no active cell developed in this case (Figs. 4a and 5a). The fractional area of updraft cells over the whole computational domain is the largest throughout the depth in the MIDLATM-W case. The MIDLATD-C case shows smaller area of updraft coverage than the MIDLATM-W case but still much larger area than the TROPICS case. 
The areal coverage in MIDLATD-W is the smallest among the thermodynamic profiles, obviously owing to the absence of active cells. Sensitivity to the initialization method is much larger in the midlatitude than in the tropics environment.

Fig. 9 demonstrates the vertical distribution of the updraft statistics for the low-level, weak shear case. If the updraft characteristics indicated in Fig. 9 are compared with those in Fig. 8, it is seen that the updraft statistics among the thermodynamic conditions are similar with each other except for the MIDLATD-W case. With the low-level, weak shear, the MIDLATD-W case indicates stronger updrafts and comparable area of updraft coverage than the TROPICS cases. These updraft statistics in the MIDLATD-W case become increased from those obtained with the deep shear. Again, sensitivity to the initialization method is found for the MIDLATD cases, which is related to the intensity of surface cold pool and is discussed later in this section.

If the shear layer of $2.5 \mathrm{~km}$ with the wind difference of $5 \mathrm{~m} \mathrm{~s}^{-1}$ is elevated from the ground surface (low-level shear) to the height above the $2.5-\mathrm{km}$ level (mid-level shear), the convective development in the MIDLATD cases is most affected (Fig. 10). It is seen that in the MIDLATD cases convective development is significantly suppressed with the cold-pool initialization (see also Fig. 7) and the updraft maxima are significantly reduced with the warm-thermal initialization. On the other hand, the updraft statistics in the TROPICS cases are relatively unaffected by elevating the shear layer.

From these analyses on convective updrafts, it is clearly seen that the strength and areal extent of updrafts are significantly affected by the changes in the thermodynamic condition, the shear profile, and even the initialization method. The difference in the convective updraft suggests that cloud and precipitation characteristics are also affected in response to thermodynamic condition, shear profile, and initialization. Fig. 11 compares the means of total water condensate mixing ratio at the 3-km height averaged over the whole computational area during 2 and 6 hours. It is indicated that the highest water content among the thermodynamic conditions is seen in the MIDLATM-W condition for each shear case, and that the second largest water content is found in the MIDLATD-C condition 
only for the surface-based shears. It is also seen that the difference between the initialization methods is smaller in the TROPICS than in the MIDLATD cases. The MIDLATD-W cases indicate the absence of water condensates.

In Fig. 12, the mean precipitation intensity averaged over the computational area and over the period during 2 and 6 hours is shown. The standard deviation calculated from the time series of area-mean precipitation intensity is also included in this figure. The temporal and spatial mean of precipitation intensity is proportional to the total accumulation of precipitation over the computational area during the specified time frame. In accordance with the updraft statistics and total water content produced at the $3-\mathrm{km}$ height, the MIDLATM-W condition produces the largest amount of precipitation for all the shear cases. On the other extreme, there is virtually no precipitation in the MIDLATD-W condition for every shear profile, corresponding to little amount of water condensate generated in this thermodynamic condition (Fig. 11). Furthermore, the lower atmosphere is quite dry (Fig. 1b), and hence precipitation produced evaporates before reaching the ground surface. Although the updraft appears to be strong in terms of its peak value, precipitation is not produced correspondingly. It was previously identified that the statistics of maximum updraft and mean precipitation do not necessarily agree with each other (Weisman and Rotunno, 2004).

In the MIDLATD-C case, precipitation is produced if the shear layer is based at the surface. On the other hand, in the TROPICS cases, the sensitivity to the initialization method as seen in the MIDLATD cases is not so significant. Depending on the height and intensity of the shear layer, the mean precipitation in the warm and the cold initialization varies, but the variation in TROPICS is less sensitive to the shear profile, compared with the results in the MIDLATD cases.

Precipitation maxima exhibit contrasting characteristics. Fig. 13 shows the mean and standard deviation obtained from the time series of the maximum precipitation intensity derived over the computational area during the period of 2 and 6 hours. For each shear profile the strongest precipitation intensity is simulated not necessarily in the MIDLATM-W condition. It is seen in Fig. 13 that the maximum precipitation intensity in the TROPICS-W condition is comparable to, and for 
some shear cases even larger than, that in the MIDLATM-W condition. In the TROPICS-C condition the precipitation intensity maxima are seen to be comparable to those in MIDLATM-W for the low-level, strong shear and the deep shear. In this way, the maximum precipitation intensity in the tropical environment can be as strong as that simulated in MIDLATM-W. In contrast, the MIDLATD conditions produce much weaker precipitation maxima, except for the case initialized by the cold pool in the surface-based shear.

The different responses of the mean and the peak intensity of precipitation to the thermodynamic condition and the shear profile were identified in Takemi (2007a) and will be discussed in section 3.3.

The intensity of the simulated squall lines can be interpreted as a result of the interaction between ambient vertical shear and cold pool (Rotunno et al., 1988; Weisman and Rotunno, 2004). In order to diagnose the relationship between vertical shear and cold pool, we examine the intensity of cold pool $C$. The equation used in Weisman and Rotunno (2004) is employed here to define $C$ but including the negative effects of ice-phase water substances on buoyancy. As in Takemi (2007a; 2007b), the parameter $C$ is calculated in the cold pool region (defined as negative anomalies of virtual potential temperature greater than $-1 \mathrm{~K}$ ) between the eastward-moving leading edge and $20-\mathrm{km}$ behind at each output time during 2 and 6 hours. Fig. 14 shows the temporal mean and the standard deviation of the cold-pool intensity for all the experiment cases. In the MIDLATM-W cases, the intensity of cold pool ranges between 15 and $20 \mathrm{~m} \mathrm{~s}^{-1}$. Because the strongest squall lines are achieved by the equal amount of vertical shear $\Delta U$ to $C$, so called the optimal shear (Rotunno et al., 1988), the strong shears become optimal. According to Weisman and Rotunno (2004), the shear counteracting with the cold pool should be assessed by the surface-based shear below the 5-km height, and the ratio $C / \Delta U$ is about $1-1.5$. Therefore, with those cold-pool intensities, the optimal cases are the low-level strong shear and the deep shear; these shear cases well correspond to the two highest mean precipitation shown in Fig. 12. In the drier case of MIDLATD-C, the strong cold pool can only be balanced by the optimal cases of the low-level, strong and the deep shear. In other 
words, in drier cases the $C / \Delta U$ relationship becomes critical in determining the intensity of squall lines (Takemi 2006). On the other hand, in the TROPICS thermodynamic conditions the intensities of cold pool are around $10 \mathrm{~m} \mathrm{~s}^{-1}$, generally weaker those of MIDLATM-W and MIDLATD-C. Therefore, not only the strong shear but also the weak shear is able to balance the cold-pool intensity, explaining higher amount of mean precipitation in both the strong and the weak shear case in the TROPICS environment shown in Fig. 12.

Although the vertical distribution of CAPE is the same in MIDLATD-C and TROPICS, the cold-pool intensity is stronger in MIDLATD-C than in TROPICS with the surface-based shears. Comparing the total water content at the $3-\mathrm{km}$ level (Fig. 11) and the mean precipitation (Fig. 12), it is suggested that the evaporative cooling of falling precipitation plays a role in producing stronger cold pool in MIDLATD-C. Therefore, it is important to take into account the difference in the low-level relative humidity under the same CAPE distribution in comparing the mean precipitation between MIDLATD-C and TROPICS.

\subsection{Synthesis and discussion}

From the analyses of updraft and precipitation statistics described in section 3.2, all the measures (but except the maximum precipitation intensity) indicated that the MIDLATM-W case produced the most intensified and organized convective systems for all the shear cases. This is clearly explained by the initial thermodynamic profile. In MIDLATM-W, the CAPE amount for air parcels originating at levels from the surface to about $1 \mathrm{~km}$ exceeds $3000 \mathrm{~J} \mathrm{~kg}^{-1}$ and is larger than $500 \mathrm{~J} \mathrm{~kg}^{-1}$ for parcels at levels up to the 2-km height, decreasing to zero above the 3-km height, although CAPE for the surface air parcel is the same among the three thermodynamic profiles (Fig. 2). The difference in the intensity of the simulated squall lines between the MIDLATM-W case and the other two thermodynamic conditions is interpreted as the consequence of the difference in the vertical distribution of CAPE. 
Sensitivity to the initialization method is pronounced for the MIDLATD cases, compared with the TROPICS cases. In the MIDLATD-W case, virtually no precipitation is produced (Fig. 12); this is because initial thermal did not strongly develop in the dry environment and hence was not able to produce cold pool. In contrast, the MIDLATD-C case simulated a squall-line organization and active convective cells along the gust front of cold pool for the shears based at the surface. In order to examine the differences of the simulated squall lines under the MIDLATD and the TROPICS condition we compare the results of TROPICS with those of MIDLATD-C for the cases with the surface-based shears in the following. Note that the vertical distribution of CAPE between MIDLATD and TROPICS is similar to each other.

All the updraft statistics examined here, that is, the domain maxima, the vertical distribution of means and maxima, and the area-coverage of updraft cores, indicate that the convective systems simulated in the MIDLATD-C case are much stronger than those in the TROPICS cases. This difference is considered to be due to the difference in base-state temperature lapse rate. From the potential temperature profile shown in Fig. 1a it is understood that the temperature lapse rate is smaller and more close to the moist adiabat in TROPICS than in MIDLATD. This suggests that the temperature excess obtained for an adiabatically lifted air parcel from the base-state environment becomes smaller in TROPICS than in MIDLATD, resulting in weaker acceleration due to buoyancy in TROPICS. Therefore, updrafts are generally weaker in TROPICS than in MIDLATD-C.

On the other hand, the precipitation statistics, i.e., the means and the maxima of precipitation intensity, show a different feature. The mean precipitation intensity, which is proportional to the accumulated precipitation during the same time period, in MIDLATD-C is almost comparable to that in TROPICS for the surface-based shears, although the total water content at a higher level is larger in MIDLATD-C than in TROPICS. In contrast, it is not true that the maximum precipitation in MIDLATD-C is consistently larger than that in TROPICS. The different responses of the mean and the peak intensity of precipitation to the thermodynamic condition and the shear profile are considered to be due to negative effects of dilution of convective cores with the environment and 
the resultant loss of buoyancy. The negative effects of dry air on convective strength were found in some numerical studies (Tompkins, 2001; James and Markowski, 2010). In the temporal mean sense, the updraft cores are more negatively affected by the environmental dilution, if the strength of updrafts is weaker and their size is smaller. Weaker updrafts lead to weaker convective system as a whole, and hence a smaller amount of total precipitation produced by the convective system. Therefore, the simulated convective clouds in the TROPICS cases, which have weaker and smaller updraft cores than in the MIDLATD-C and MIDLATM-W cases, become less intensified and less organized, leading to a smaller amount of total precipitation. This is the reason of the response shown in Fig. 12, since the mean precipitation is proportional to the total precipitation. In other words, the total amount of precipitation is strongly controlled by the degree of organization and intensification of a convective system as a whole. On the other hand, the instantaneous maxima of precipitation intensity are not directly related to the organization of convective system as a whole but dependent on the intensity of individual convective cells that are dependent on CAPE.

A seemingly peculiar behavior of maximum precipitation intensity was also identified in Takemi (2010), and may be related to the total moisture content available for the development of a convective system, that is, precipitable water content. As mentioned in section 2, the largest amount of precipitable water among the three thermodynamic conditions is TROPICS, which appears to correspond to the behavior of the maximum precipitation intensity. It was found from the analyses of an observed derecho-producing convective system that high precipitable water is an important factor in generating the significant derecho-producing convective event (Coniglio et al. 2011). In the present study, we do not take into account the sensitivity to precipitable water, which remains to be a future issue.

Takemi (2010) emphasized the importance of temperature lapse rate (relevant to the magnitude of buoyancy) and the vertical CAPE distribution. It was shown that mean precipitation intensity increases with the increase in temperature lapse rate if CAPE for surface air parcel is the same. However, Takemi (2010) did not separate temperature lapse rate and vertical CAPE distribution in 
prescribing the thermodynamic conditions: if the temperature lapse rate decreased, the layer having significant amount of CAPE at the same time became shallower. In contrast, the present study controls the vertical CAPE distribution as shown in Fig. 2. Therefore, the difference in precipitation intensity between MIDLATM-W and TROPICS (or MIDLATD-C) is attributed to the difference in the vertical distribution of CAPE for air parcels originating at elevated levels, while the comparable precipitation intensity between MIDLATD-C and TROPICS is attributed to the similarity of the vertical distribution of CAPE.

Another point to note here is that the dependence of the simulated convective system to the initialization method appears differently in response to the prescribed thermodynamic conditions. Among the cases examined here, the MIDLATD condition shows a pronounced sensitivity to the initialization method. This is considered to be due to the dryness below the 6-km height, which is detrimental to the development of convective clouds especially at the early stage of the convective system. If the initial clouds attain sufficient intensity and produce cold pools that play a critical role in generating new convective cells, the intensity of convective clouds as a system (i.e., squall line) is established and hence maintains itself spontaneously (the MIDLATD-C case). On the other hand, if the initial clouds do not attain intensity for driving a spontaneous mechanism, a convective system does not develop (i.e., the strong shears and the deep shear in the MIDLATD-W condition). The other thermodynamic conditions, that is, MIDLATM and TROPICS, are characterized by higher relative humidity than the MIDLATD case, and are therefore more favorable for the development of convective clouds throughout the lifetime. The sensitivity to the initialization method seen in the present experiments suggests that the diagnosis of environmental thermodynamic conditions is able to explain the structure and intensity of convective systems at their mature stage but is not capable of predicting the initiation of convective systems from an undisturbed state.

\section{Conclusions}


The present study investigated the sensitivity of the structure and intensity of squall lines to thermodynamic conditions having either a tropical, oceanic or a midlatitude, continental feature by conducting a set of numerical experiments under various temperature, moisture, and shear conditions and with different initialization methods. In general CAPE is one of the important parameters in diagnosing instability of atmospheric stratification; however, CAPE is assessed mostly for surface air parcels. Based on the studies of Takemi and Satomura (2000) and Takemi (2010), we specifically focused on CAPE for air parcels originating not only at the surface but also at elevated levels and thus took into account the vertical distribution of CAPE in the present numerical experiments. By employing the observed sounding for a squall-line case over the tropical western Pacific during TOGA-COARE and a midlatitude-type sounding representative to convective storms over the Great Plains in the United States, we set three types of thermodynamic conditions and made the vertical distribution of CAPE similar between the tropical and the midlatitude condition in addition to a very unstable state having a deep layer of the CAPE distribution. system are significantly regulated by the temperature lapse rate, which is regarded as a proxy for the vertical profile of buoyancy for an adiabatically lifted air parcel. An environment with a larger lapse rate leads to the development of stronger updrafts and a wider updraft area within a convective system. In other words, the vertical profile of buoyancy that is closely relevant to the temperature analyses.

The dependence of mean precipitation intensity produced by a convective system to environmental thermodynamic conditions is well explained by the vertical distribution of CAPE. If the layer hosting a significant amount of CAPE for air parcels originating not only at the surface but 
also at elevated heights becomes deeper with the surface-based CAPE unchanged, the precipitation amount of a convective system increases. In contrast, if the vertical distribution of CAPE is unchanged, the precipitation amount remains similar. For example, the change in temperature lapse rate but with the profile of CAPE being unchanged will not lead to the change in precipitation amount produced by a convective system. Therefore, it is concluded that the shape of the vertical distribution of CAPE for air parcels originating at different levels affects the precipitation amount generated by a convective system.

It is suggested from the numerical experiments examining the sensitivity to the initialization method that the diagnosis of environmental thermodynamic conditions is able to explain the structure and intensity of convective systems at their mature stage but is not capable of predicting the initiation of convective systems from an undisturbed state.

The importance of the vertical distribution of CAPE implies that precipitation characteristics in a future climate under global warming may be explained by thermodynamics conditions. For example, Takemi et al. (2012) and Takemi (2012) examined the environmental stability conditions for the development of convective precipitation in synoptically undisturbed situations for a case over the Tokyo metropolitan area in Japan by using numerical outputs of the present climate and a future climate condition simulated with a 20-km grid general circulation model (Mizuta et al., 2012). It was demonstrated that under a future global warming the environmental conditions for the convective precipitation indicate decreased temperature lapse rate and increased moisture content in the lower troposphere. The changes in the combination of temperature and moisture lead to the change in the vertical distribution of CAPE, and therefore, the diagnosis of the CAPE distribution would give a guide to understand the behavior of precipitation induced by convective systems.

\section{Acknowledgments}

The comments from the three anonymous reviewers were greatly acknowledged to improve the original manuscript. This work was supported by the grant under Strategic Programs for Innovative 
Research (SPIRE)-Field 3 "Projection of Planet Earth Variations for Mitigating Natural Disasters".

The GFD Dennou Library was used for drawing some of the figures.

\section{References}

Chin, H.-N. S., Fu, Q., Bradley, M. M., Molenkamp, C. R., 1995: Modeling of a tropical squall line in two dimensions: Sensitivity to radiation and comparison with a midlatitude case. J. Atmos. Sci. $52,3172-3193$.

Coniglio, M. C., Corfidi, S. F., Kain, J. S., 2011. Environmental and early evolution of the 8 May 2009 derecho-producing convective system. Mon. Wea. Rev. 139, 1083-1102.

Cotton, W. R., Bryan, G. H., Van den Heever, S. C., 2011. Storm and cloud dynamics. Academic Press. 809 pp.

Deardorff, J. W., 1980. Stratocumulus-capped mixed layers derived from a three-dimensional model. Boundary-Layer Meteor. 18, 495-527.

Doswell, C. A., Rasmussen, E. N., 1994. The effect of neglecting the virtual temperature correction on CAPE calculations. Wea. Forecasting 9, 625-629.

Ferrier, B. S., Simpson, J., Tao, W.-K., 1996. Factors responsible for precipitation efficiencies in midlatitude and tropical squall simulations. Mon. Wea. Rev. 124, 2100-2125.

Fovell, R. G., Mullendore, G. L., Kim, S.-H., 2006. Discrete propagation in numerically simulated nocturnal squall lines. Mon. Wea. Rev. 134, 3735-3752.

Guy, N., Rutledge, S. A., Cifelli, R., 2011. Radar characteristics of continental, coastal, and maritime convection observed during AMMA/NAMMA. Quart. J. Roy. Meteor. Soc. 137, 1241-1256.

Houze, R. A., 1993. Cloud dynamics. Academic Press. 573 pp.

Igau, R. C., LeMone, M. A., Wei, D., 1999. Updraft and downdraft cores in TOGA COARE: Why so many buoyant downdraft cores? J. Atmos. Sci. 56, 2232-2245. 
James, R. P., Markowski, P. M., 2010. A numerical investigation of the effects of dry air aloft on deep convection. Mon. Wea. Rev. 138, 140-161.

Jorgensen, D. P., LeMone, M. A., 1989. Vertical velocity characteristics of oceanic convection. J. Atmos. Sci. 46, 621-640.

Laing, A. G., Fritsch, J. M., 1997. The global population of mesoscale convective complexes. Quart. J. Roy. Meteor. Soc. 123, 389-405.

LeMone, M. A., Ziper, E. J., 1980. Cumulonimbus vertical velocity events in GATE. Part I: Diameter, intensity and mass flux. J. Atmos. Sci. 37, 2444-2457.

Lucas, C., Zipser, E. J., LeMone, M. A., 1994a. Vertical velocity in oceanic convection off tropical Australia. J. Atmos. Sci. 51, 3183-3193.

Lucas, C., Zipser, E. J., LeMone, M. A., 1994b: Convective available potential energy in the environment of oceanic and continental clouds: Correction and comments. J. Atmos. Sci. 51, 3829-3830.

McCaul, E. W., Jr., Cohen, C., Kirkpatrick, C., 2005: The sensitivity of simulate storm structure, intensity, and precipitation efficiency to environmental temperature. Mon. Wea. Rev. 133, 3015-3037.

Meng, Z., Yan, D., Zhang, Y., 2013. General features of squall lines in East China. Mon. Wea. Rev. $141,1629-1647$.

Mizuta, R., Yoshimura, H., Murakami, H., Matsueda, M., Endo, H., Ose, T., Kamiguchi, K., Hosaka, M., Sugi., M., Yukimoto, S., Kusunoki, S., Kitoh, A., 2012. Climate simulations using MRI-AGCM3.2 with 20-km grid. J. Meteor. Soc. Japan 90A, 233-258.

Redelsperger, J.-L., Brown, P. R. A., Guichard, F., How, C., Kawasima, M., Lang, S., Montmerle, T., Nakamura, K., Saito, K., Seman, C., Tao, W. K. and Donner, L. J., 2000. A GCSS model intercomparison for a tropical squall line observed during TOGA-COARE. I: Cloud-resolving models. Q.J.R. Meteorol. Soc. 126, 823-863.

Rotunno, R., Klemp, J. B., Weisman, M. L., 1988: A theory for strong, long-lived squall lines. J. 
Atmos. Sci. 45, 463-485.

Skamarock, W. C., Klemp, J. B., Dudhia, J., Gill, D. O., Barker, O. M., Duda, M. G., Huang, X. Y., Wang, W., Powers, J. G., 2008: A description of the Advanced Research WRF Version 3. NCAR Tech. Note, 475, $113 \mathrm{pp}$.

Takemi, T., 2006. Impacts of moisture profile on the evolution and organization of midlatitude squall lines under various shear conditions. Atmos. Res. 82, 37-54.

Takemi, T., 2007a. Environmental stability control of the intensity of squall lines under low-level shear conditions. J. Geophy. Res. 112, D24110.

Takemi, T., 2007b. A sensitivity of squall line intensity to environmental static stability under various shear and moisture conditions. Atmos. Res. 84, 374-389.

Takemi, T., 2010. Dependence of the precipitation intensity in mesoscale convective systems to temperature lapse rate. Atmos. Res. 96, 273-285.

Takemi, T., 2012. Projected regional-scale changes in atmospheric stability condition for the development of summertime convective precipitation in the Tokyo metropolitan area under global warming. Hydrol. Res. Lett. 6, 17-22.

Takemi, T., Satomura, T., 2000. Numerical experiments on the mechanisms for the development and maintenance of long-lived squall lines in dry environments. J. Atmos. Sci. 57, 1718-1740.

Takemi, T., Rotunno, R., 2003. The effects of subgrid model mixing and numerical filtering in simulations of mesoscale cloud systems. Mon. Wea. Rev. 131, 2085-2101.

Takemi, T., Nomura, S., Oku, Y., Ishikawa, H., 2012. A regional-scale evaluation of changes in environmental stability for summertime afternoon precipitation under global warming from super-high-resolution GCM simulations: A study for the case in the Kanto Plain. J. Meteor. Soc. Japan, 90A, 189-212.

Tao, W.-K., Simpson, J., 1993. The Goddard cumulus ensemble model. Part I: Model description. Terr. Atmos. Oceanic Sci. 4, 35-72.

Tao, W. -K., Simpson, J., Sui, C. H., Ferrier, B., Lang, S., Scala, J., Chou, M. D., Pickering, K., 
1993. Heating, moisture, and water budgets of tropical and midlatitude squall lines: Comparisons and sensitivity to longwave radiation. J. Atmos. Sci. 50, 673-690.

Tao, W-K., Scala, J. R., Ferrier, B., Simpson, J., 1995. The effect of melting processes on the development of a tropical and a midlatitude squall line. J. Atmos. Sci. 52, 1934-1948.

Tao, W.-K, Simpson, J., Baker, D., Braun, S., Chou, M.-D., Ferrier, B., Johnson, D., Khain, A., Lang, S., Lynn, B., Shie, C.-L., Starr, D., Sui, C.-H., Wang, Y., Wetzel, P., 2003. Microphysics, radiation and surface processes in the Goddard Cumulus Ensemble (GCE) model. Meteor. Atmos. Phys. 82, 97-137.

Tompkins, A. M., 2001. Organization of tropical convection in low vertical wind shears: The role of water vapor. J. Atmos. Sci. 58, 529-545.

Trier, S. B., Skamarock, W. C., LeMone, M. A., Parsons, D. B., Jorgensen, D. P., 1996. Structure and evolution of the 22 February 1993 TOGA COARE squall line: Numerical simulations. J. Atmos. Sci. 53, 2861-2886.

Wei, D., Blyth, A. M., Raymond, D. J., 1998: Buoyancy of convective clouds in TOGA COARE. J. Atmos. Sci. 55, 3381-3391.

Weisman, M. L., Klemp, J. B., 1982. The dependence of numerically simulated convective storms on vertical wind shear and buoyancy. Mon. Wea. Rev. 110, 504-520.

Weisman, M. L., Klemp, J. B., Rotunno, R., 1988. Structure and evolution of numerically simulated squall lines. J. Atmos. Sci. 58, 1630-1649.

Weisman, M. L., Rotunno, R., 2004. "A theory for strong long-lived squall lines" revisited. J. Atmos. Sci. 61, 361-382.

Zipser, R. J., LeMone, M. A., 1980. Cumulonimbus vertical velocity events in GATE. Part II: Synthesis and model core structure. J. Atmos. Sci. 37, 2458-2469. 


\section{List of Table Captions}

Table 1 . The thermodynamic profile and initialization method of the numerical experiment. See text for the definitions of TROPICS and MIDLAT. 
Table 1. The thermodynamic profile and initialization method of the numerical experiment. See text for the definitions of TROPICS and MIDLAT.

\begin{tabular}{lccc}
\hline \hline Exp series & Temperature profile & Relative humidity & Initial disturbance \\
\hline TROPICS-W & TROPICS & TROPICS & Warm \\
\hline TROPICS-C & TROPICS & TROPICS & Cold \\
\hline MIDLATD-W & MIDLAT & MIDLAT, dry & Warm \\
\hline MIDLAD-C & MIDLAT & MIDLAT, dry & Cold \\
\hline MIDLATM-W & MIDLAT & MIDLAT, moist & Warm \\
\hline \hline
\end{tabular}




\section{List of Figures}

Fig. 1. The base-state vertical profiles of (a) potential temperature and (b) relative humidity for the cases of TROPICS (red), MIDLATD (green), and MIDLATM (blue).

Fig. 2. The vertical distribution of CAPE for the cases of TROPICS (red), MIDLATD (green), and MIDLATM (blue).

Fig. 3. The vertical profiles of wind speed for the cases of (a) the low-level shears, (b) the middle-level shears, and (c) the deep shear.

Fig. 4. The horizontal cross section of vertical velocity at the $3-\mathrm{km}$ height (contoured at $3-\mathrm{m} \mathrm{s}^{-1}$ interval, solid lines for updraft and dotted lines for downdraft) and the surface gust front (bold dashed line) of eastward-moving cold pool at the simulated time of 4 hours. (a) TROPICS-W, (b) TROPICS-C, (c) MIDLATM-W, (d) MIDLATD-W, and (e) MIDLATD-C with the deep shear case $\left(10 \mathrm{~m} \mathrm{~s}^{-1}\right.$ in the $0-5 \mathrm{~km}$ layer $)$.

Fig. 5. The same as Fig. 4, except for total condensed water mixing ratio contoured at $0.0005 \mathrm{~kg}$ $\mathrm{kg}^{-1}$

Fig. 6. The same as Fig. 4, except for total condensed water mixing ratio (contoured at $0.0005 \mathrm{~kg}$ $\left.\mathrm{kg}^{-1}\right)$ for the low-level, weak shear case $\left(5 \mathrm{~m} \mathrm{~s}^{-1}\right.$ in the $0-2.5 \mathrm{~km}$ layer).

Fig. 7. The means (symbols) and standard deviations (bars) of the maximum updraft speed in the computational domain during 2 and 6 hours for all the numerical experiments.

Fig. 8. The temporal averaged vertical profiles of (a) the mean (solid lines) and the maximum (dashed lines) updraft speed over the updraft grids and (b) the fractional area of updraft grids over the computational area for the deep shear case $\left(10 \mathrm{~m} \mathrm{~s}^{-1}\right.$ in the $0-5 \mathrm{~km}$ layer).

Fig. 9. The same as Fig. 8, except for the low-level, weak shear $\left(5 \mathrm{~m} \mathrm{~s}^{-1}\right.$ in the $0-2.5 \mathrm{~km}$ layer $)$. 
Fig. 10. The same as Fig. 8, except for the mid-level, weak shear $\left(5 \mathrm{~m} \mathrm{~s}^{-1}\right.$ in the $2.5-5 \mathrm{~km}$ layer $)$.

Fig. 11. The means of total water condensate mixing ratio at the $3-\mathrm{km}$ height averaged over the whole computational area during 2 and 6 hours for all the numerical experiments.

Fig. 12. The mean (symbols) and standard deviation (bars) from the time series of spatially averaged precipitation intensity over the computational area during the time period of 2 and 6 hours.

Fig. 13. The same as Fig. 12, except for the maximum precipitation intensity.

Fig. 14. The same as Fig. 12, except for the intensity of cold pool. 

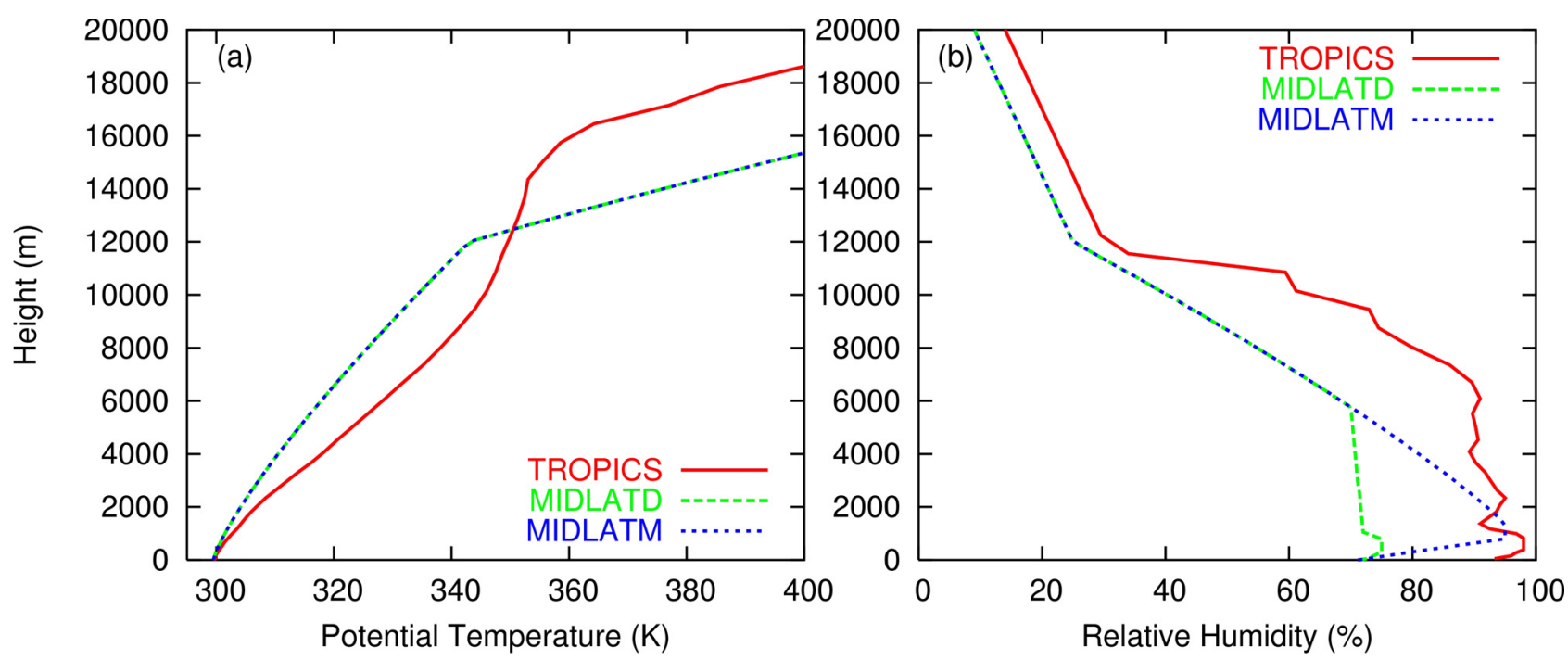

Fig. 1. The base-state vertical profiles of (a) potential temperature and (b) relative humidity for the cases of TROPICS (red), MIDLATD (green), and MIDLATM (blue). 


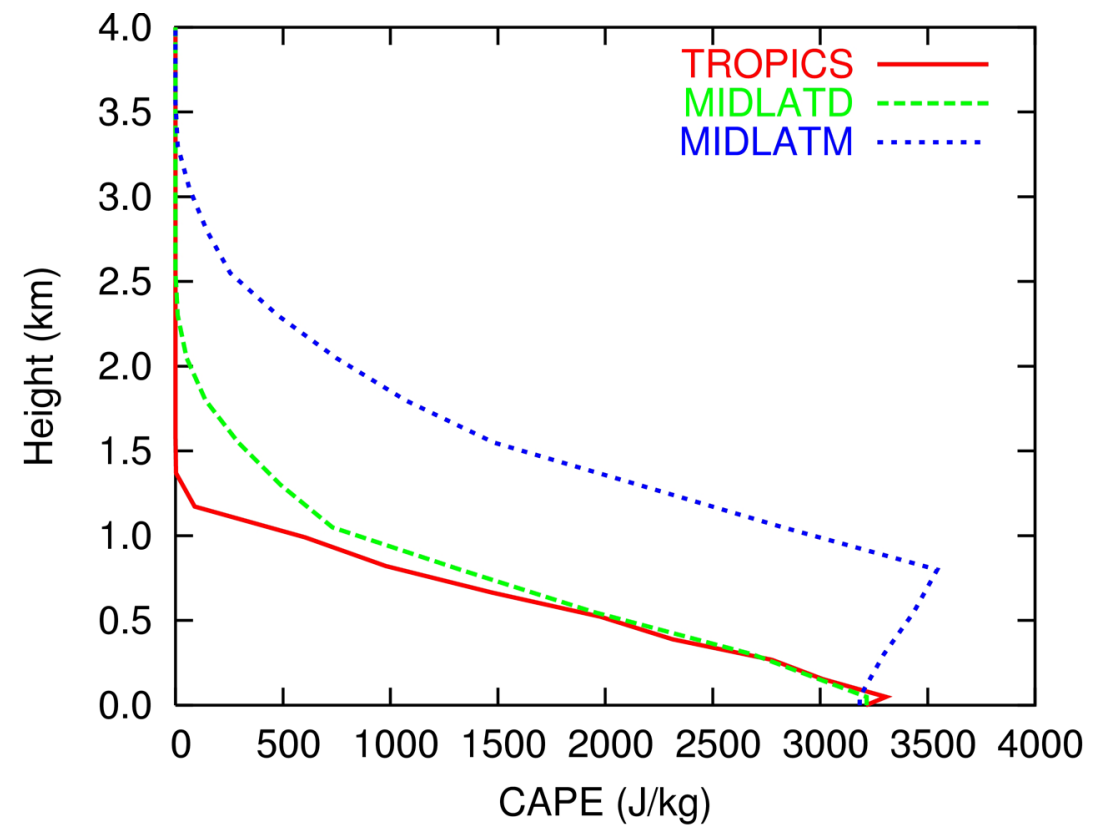

Fig. 2. The vertical distribution of CAPE for the cases of TROPICS (red), MIDLATD (green), and MIDLATM (blue). 


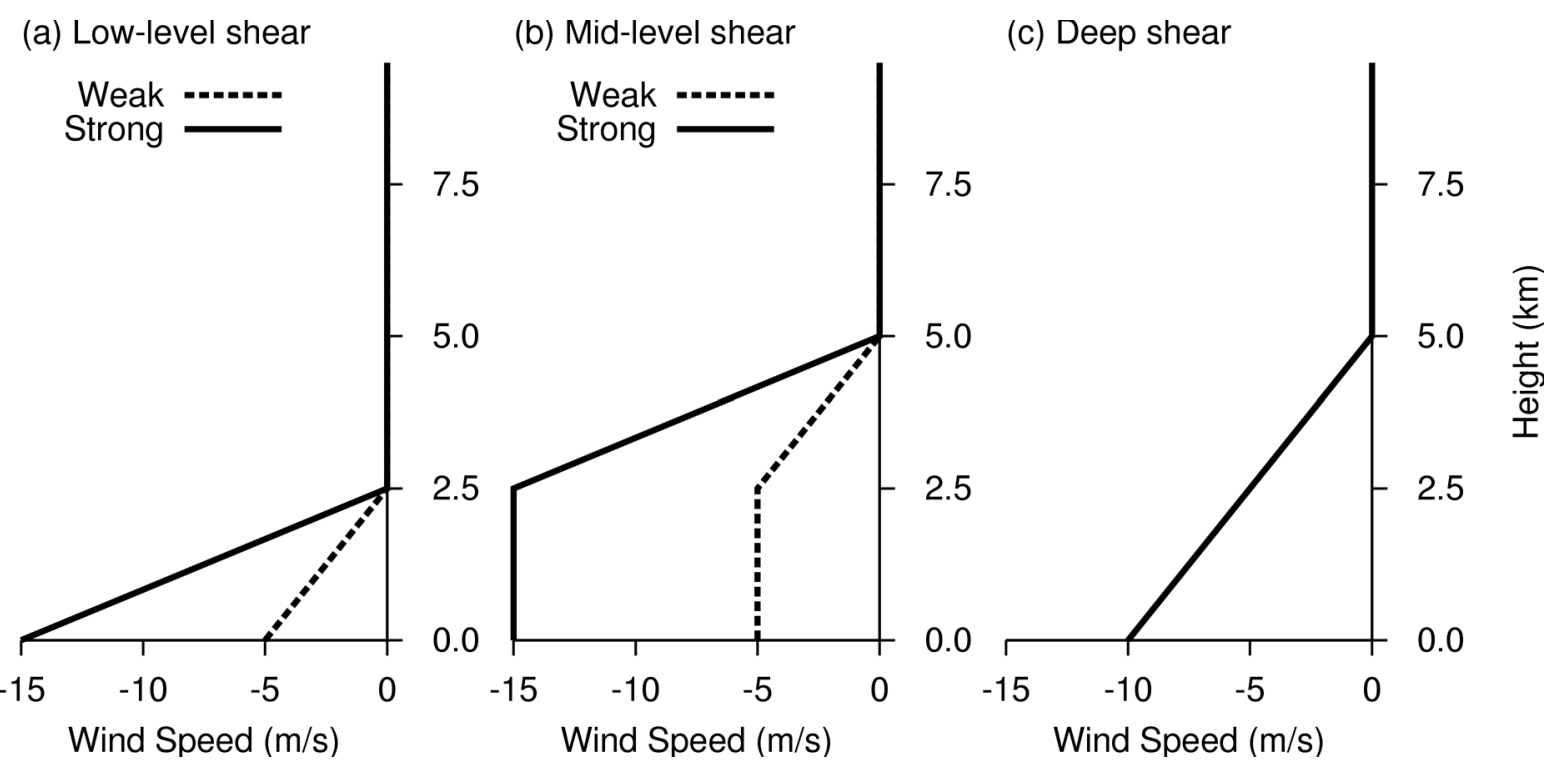

Fig. 3. The vertical profiles of wind speed for the cases of (a) the low-level shears, (b) the middle-level shears, and (c) the deep shear. 

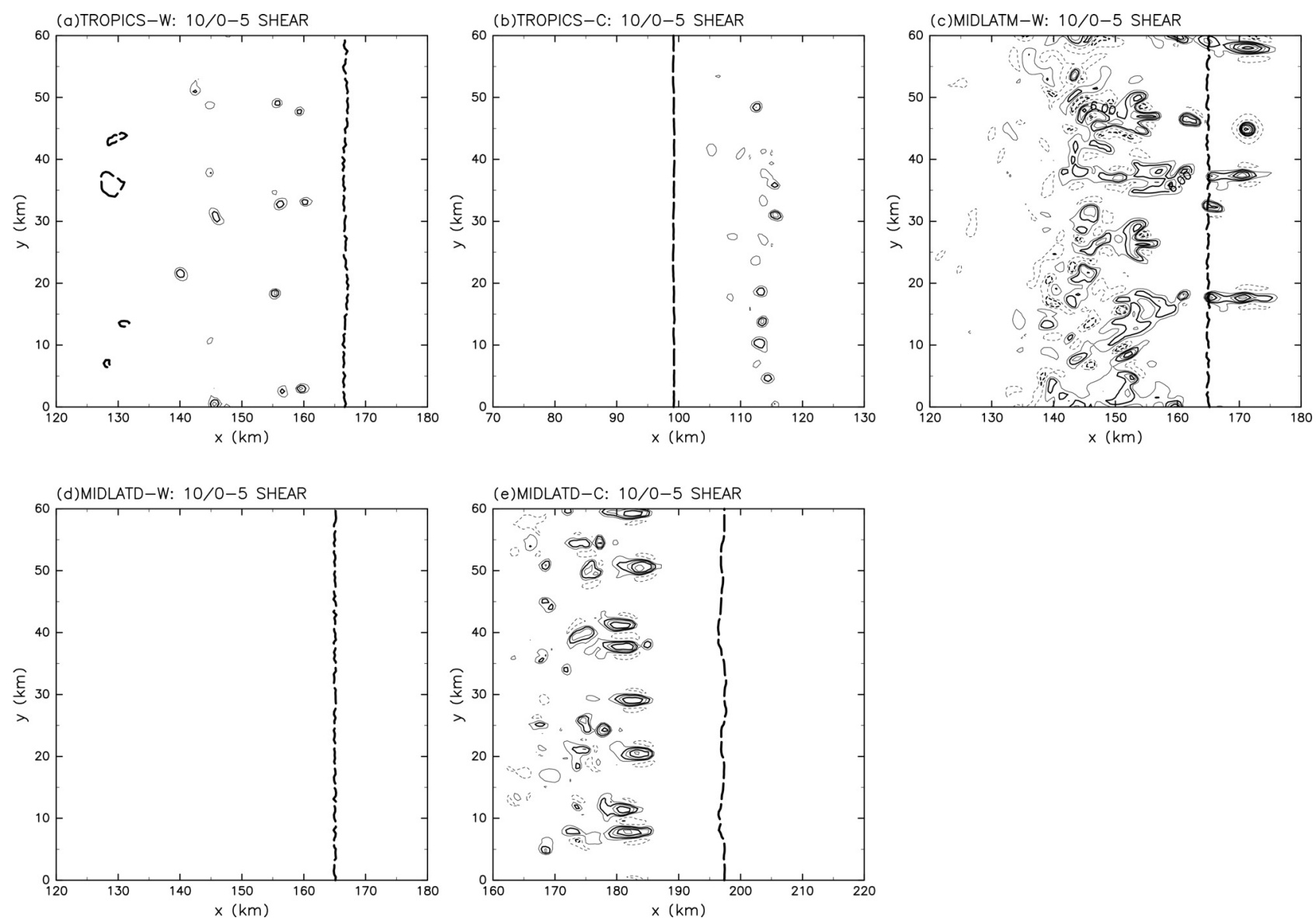

Fig. 4. The horizontal cross section of vertical velocity at the $3-\mathrm{km}$ height (contoured at $3-\mathrm{m} \mathrm{s}^{-1}$ interval, solid lines for updraft and dotted lines for downdraft) and the surface gust front (bold dashed line) of eastward-moving cold pool at the simulated time of 4 hours. (a) TROPICS-W, (b) TROPICS-C, (c) MIDLATM-W, (d) MIDLATD-W, and (e) MIDLATD-C with the deep shear case (10 $\mathrm{m} \mathrm{s}^{-1}$ in the $0-5 \mathrm{~km}$ layer). 

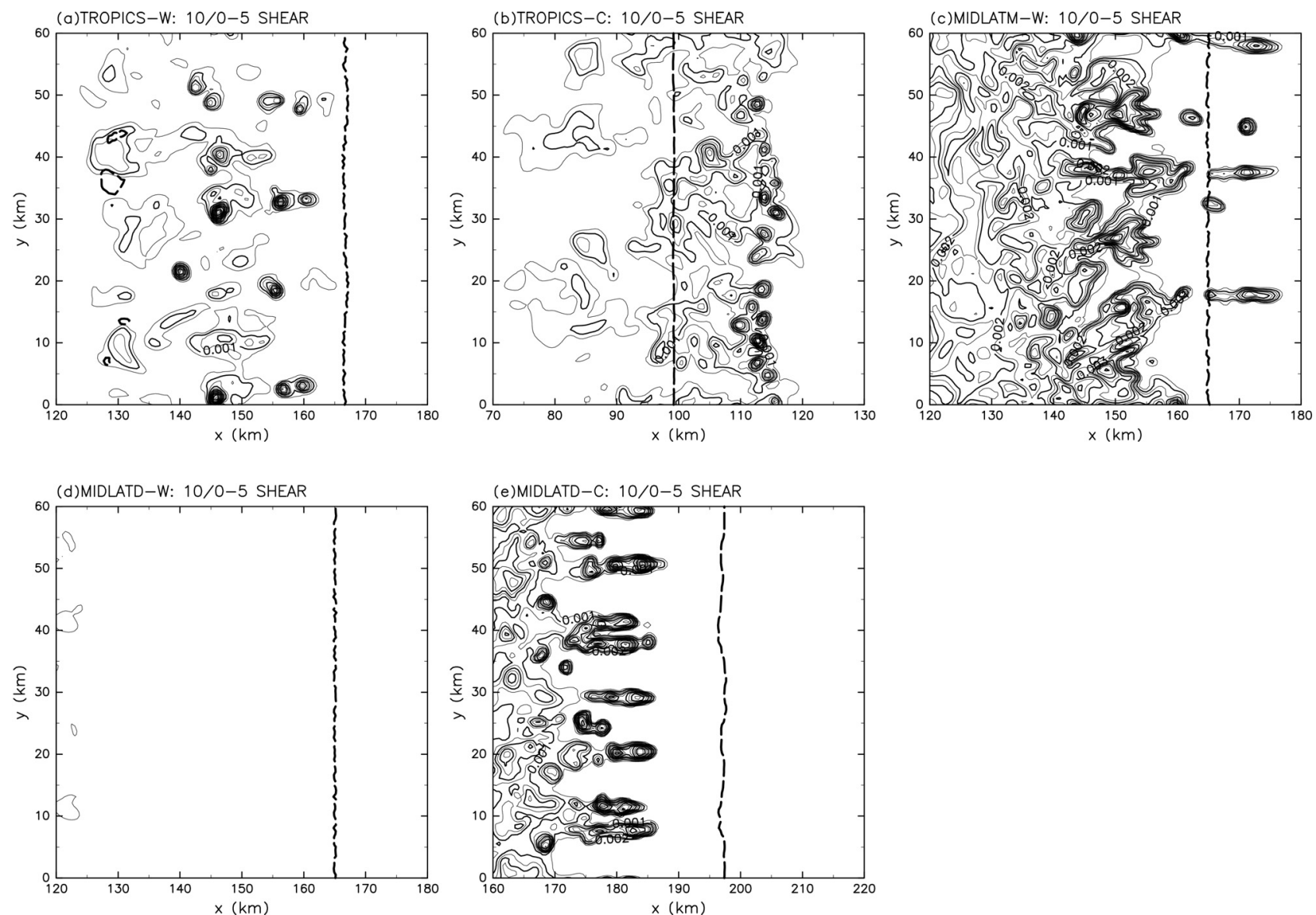

Fig. 5. The same as Fig. 4, except for total condensed water mixing ratio contoured at $0.0005 \mathrm{~kg}$ $\mathrm{kg}^{-1}$. 

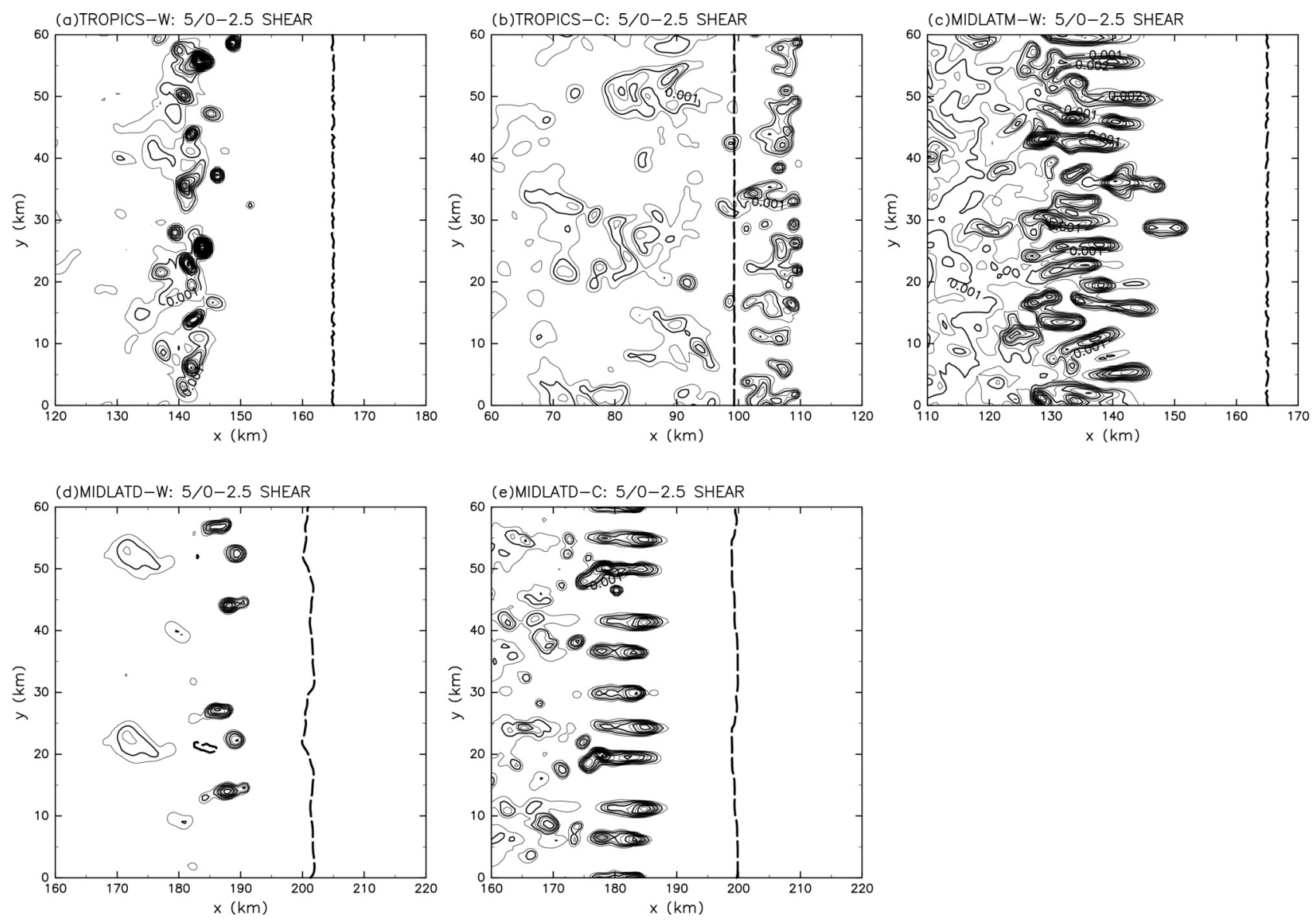

Fig. 6. The same as Fig. 4, except for total condensed water mixing ratio (contoured at $0.0005 \mathrm{~kg}$ $\left.\mathrm{kg}^{-1}\right)$ for the low-level, weak shear case $\left(5 \mathrm{~m} \mathrm{~s}^{-1}\right.$ in the $0-2.5 \mathrm{~km}$ layer). 


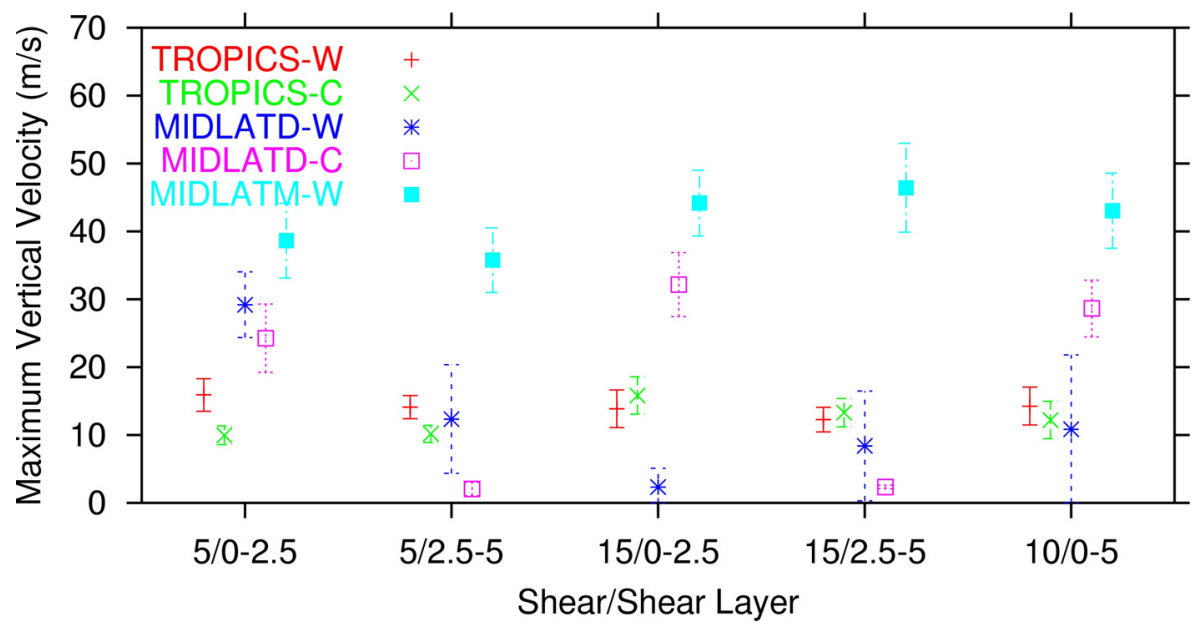

Fig. 7. The means (symbols) and standard deviations (bars) of the maximum updraft speed in the computational domain during 2 and 6 hours for all the numerical experiments. 

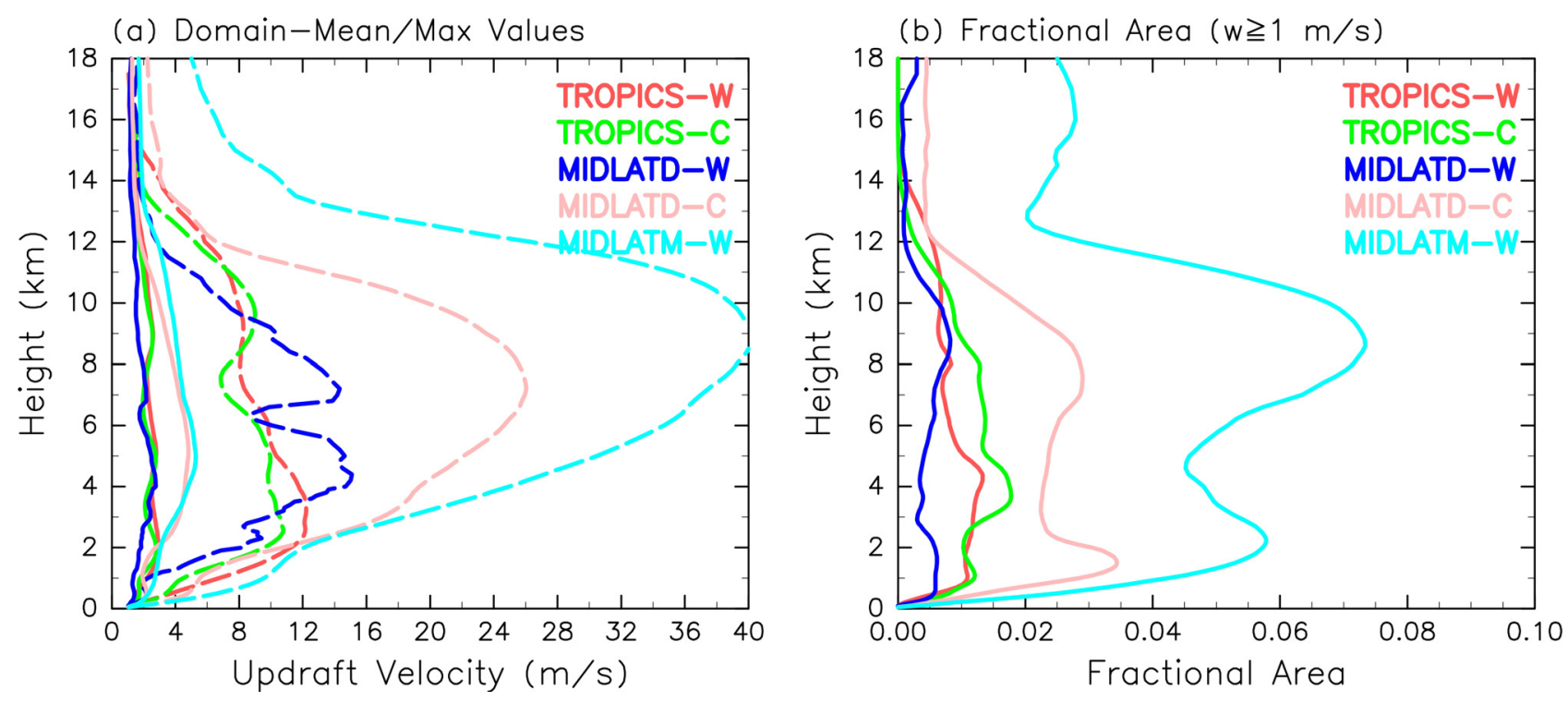

Fig. 8. The temporal averaged vertical profiles of (a) the mean (solid lines) and the maximum (dashed lines) updraft speed over the updraft grids and (b) the fractional area of updraft grids over the computational area for the deep shear case $\left(10 \mathrm{~m} \mathrm{~s}^{-1}\right.$ in the $0-5 \mathrm{~km}$ layer). 

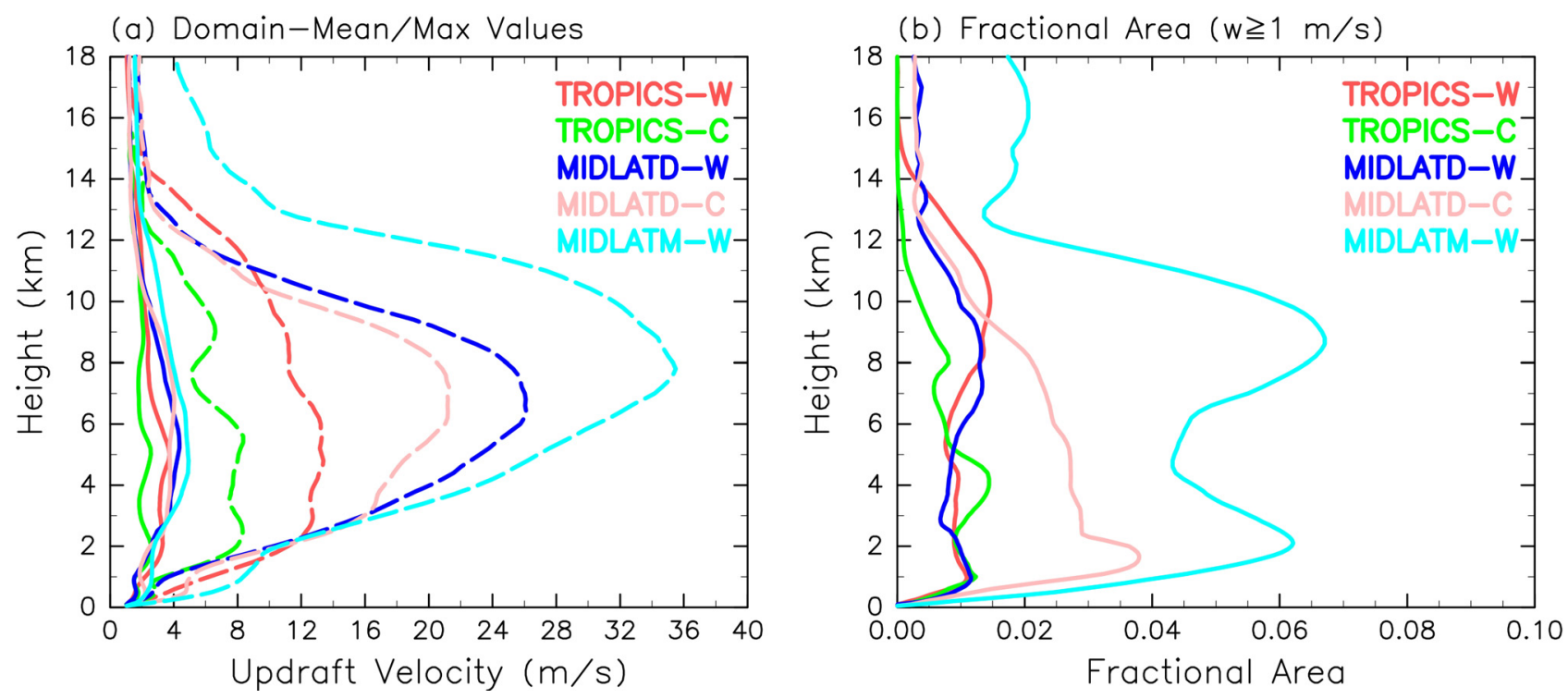

Fig. 9. The same as Fig. 8, except for the low-level, weak shear $\left(5 \mathrm{~m} \mathrm{~s}^{-1}\right.$ in the $0-2.5 \mathrm{~km}$ layer $)$. 

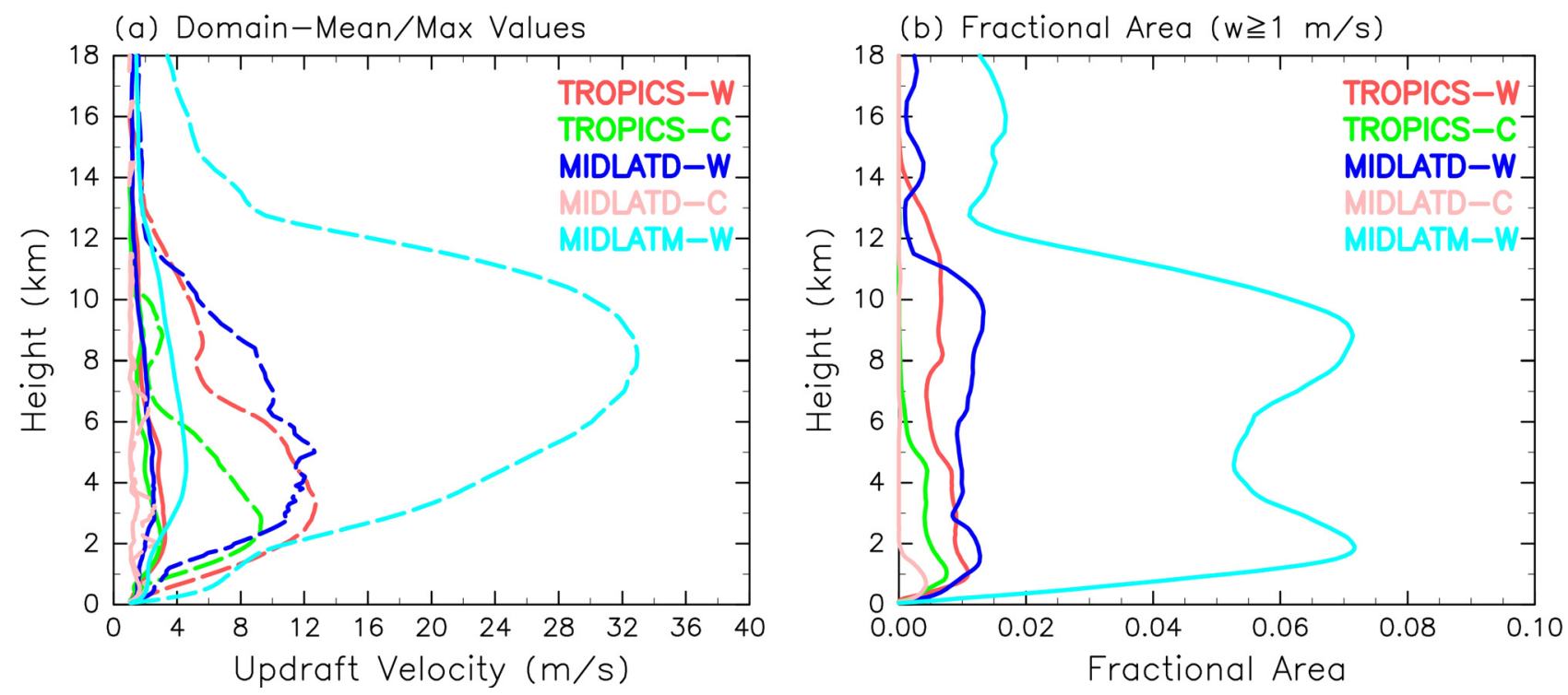

Fig. 10. The same as Fig. 8, except for the mid-level, weak shear $\left(5 \mathrm{~m} \mathrm{~s}^{-1}\right.$ in the $2.5-5 \mathrm{~km}$ layer $)$. 


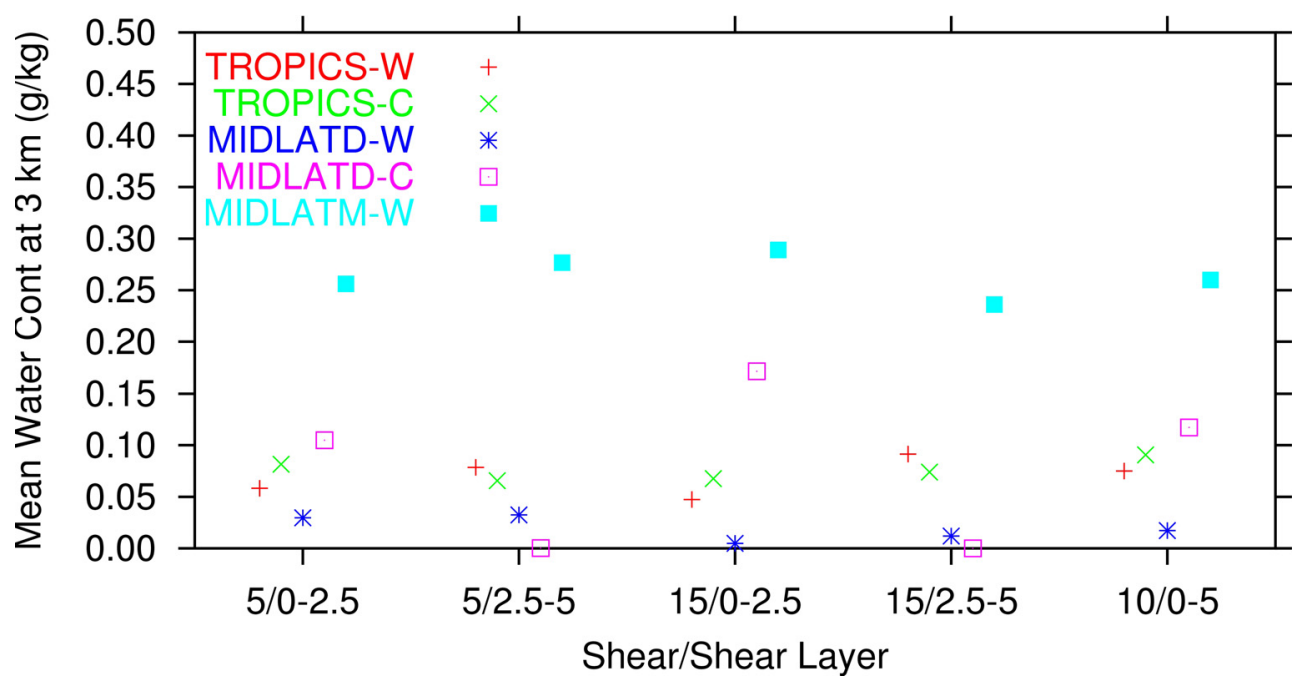

Fig. 11. The means of total water condensate mixing ratio at the $3-\mathrm{km}$ height averaged over the whole computational area during 2 and 6 hours for all the numerical experiments. 


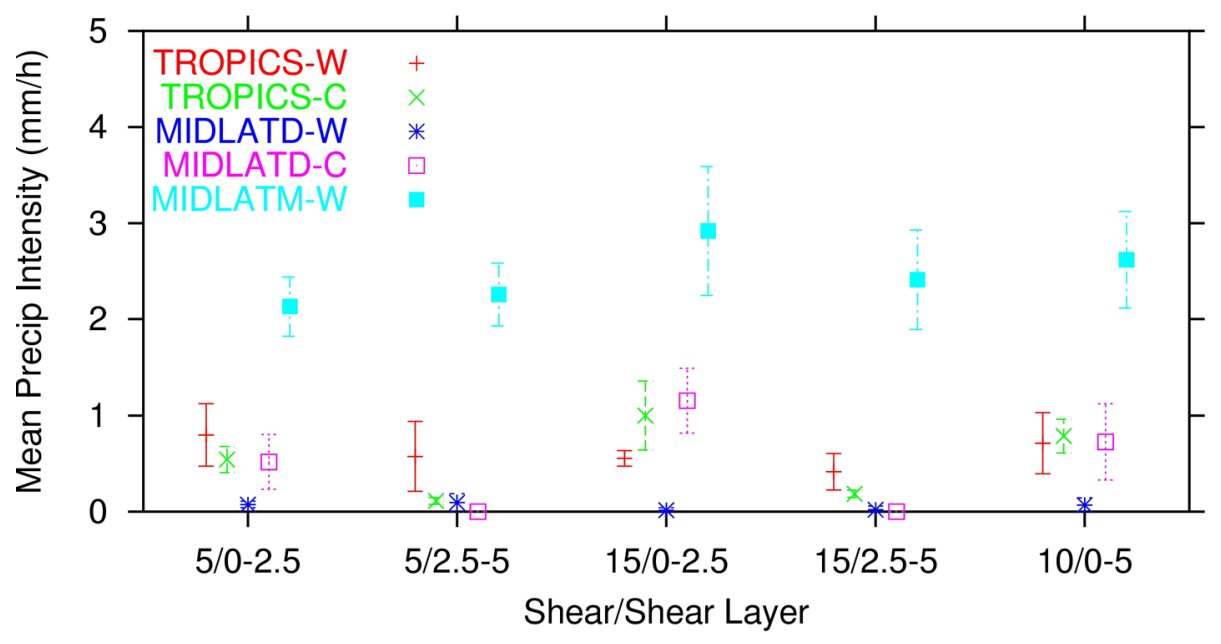

Fig. 12. The mean (symbols) and standard deviation (bars) from the time series of spatially averaged precipitation intensity over the computational area during the time period of 2 and 6 hours. 


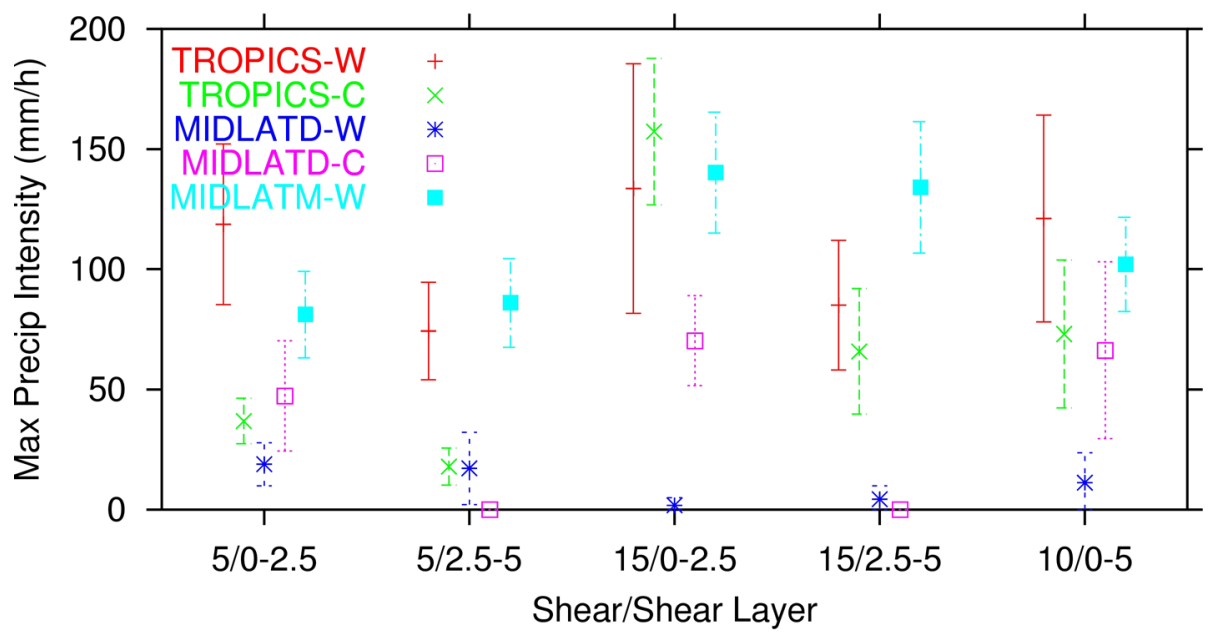

Fig. 13. The same as Fig. 12, except for the maximum precipitation intensity. 


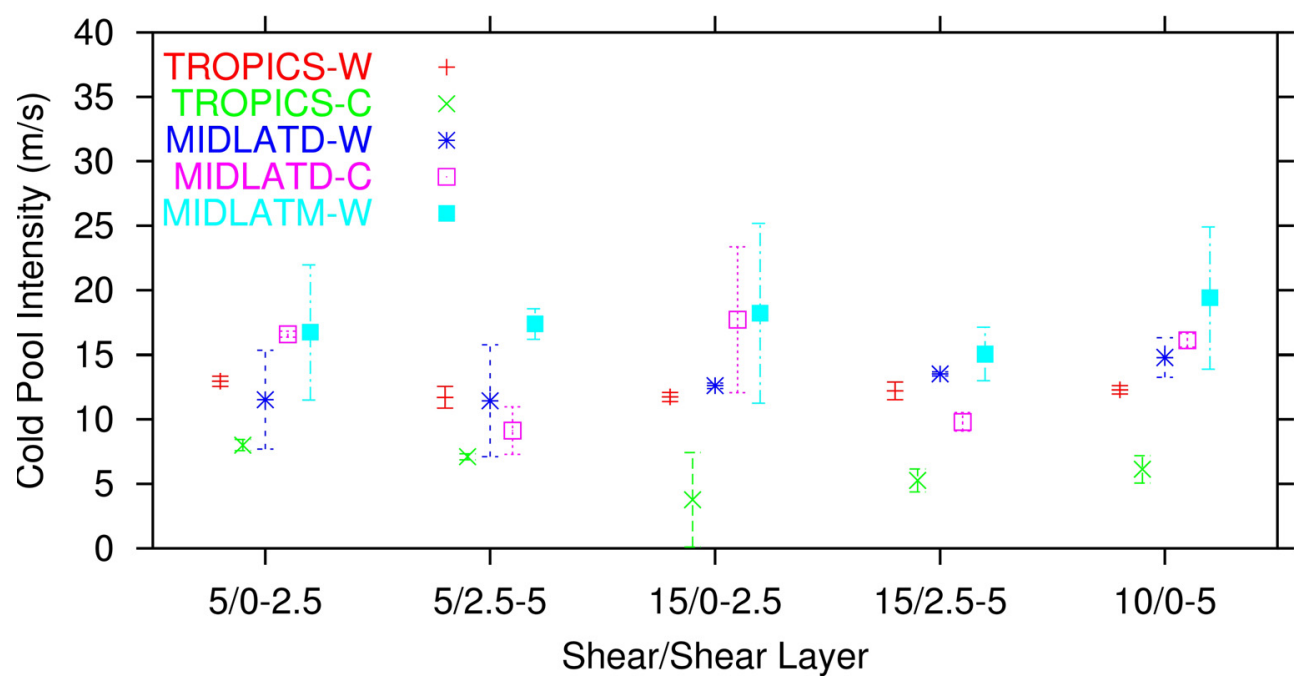

Fig. 14. The same as Fig. 12, except for the intensity of cold pool. 